Derecho arbitral 


\title{
La garantía del debido proceso en el arbitraje. El modelo español
}

\author{
Antonio Lorca Navarrete
}

\section{La sustanciación garantista de las actuaciones arbitrales}

Comenzaré rememorando que una determinada convención legislativa, concretada en la vigente LA del 2003, ha resuelto que, con la expresión "De la sustanciación de las actuaciones arbitrales" - con la que se rubrica el título V LA -, ha decidido optar. O sea, y lo diré para que se me entienda: la referida convención legislativa, concretada en la vigente LA del 2003, no opta por el término procedimiento ni por el de proceso - arbitral, se entiende - . No. Parece que - rotundamente - es así. En cambio, opta y alude - porque no me pasa desapercibido- a actuaciones arbitrales y a su sustanciación (Comentarios a la nueva... 2005, p. 239 y ss.).

* Abreviaturas utilizadas: LA: Ley española de Arbitraje vigente; LAP: Ley española de Arbitraje de Derecho Privado de 1953; RVDPA: Revista Vasca de Derecho Procesal y Arbitraje; SAPB: Sentencia de la Audiencia Provincial de Barcelona; SAPont: Sentencia de la Audiencia Provincial de Pontevedra. SAPM: Sentencia de la Audiencia Provincial de Madrid. SAPSe: Sentencia de la Audiencia Provincial de Sevilla; SAPVizc: Sentencia de la Audiencia Provincial de Vizcaya; TC: Tribunal Constitucional. 
La ya consabida convención legislativa - concretada en la vigente LA del 2003 - no debiera dar pie - pienso yo- a ningún sobresalto. No obstante, encuentro en ella - en la mencionada convención legislativa, se entiende - un par de términos que, a primera vista, parecen conciliarse bien con la mentada rúbrica y que demandan alguna puntualización. Para comenzar, se alude - y con razón, creo- en la exposición de motivos de la LA al "arbitraje como proceso que es" - véase si no el apartado VI de la mentada exposición de motivos de la vigente LA -, por lo que la antedicha alusión - concretada en ese par de términos a que aludía renglones antes-, realizada por la propia LA al "arbitraje como proceso que es", se me antoja - ahora sí- como la opción determinante porque las garantías del debido proceso sustantivo arbitral, que necesariamente han de confluir en el procedimiento a seguir en la sustanciación de las actuaciones arbitrales que se tramiten por el árbitro, se conectan con la presencia de un "proceso arbitral con todas las garantías" de "aquí y ahora", que corrige la aplicación mecanicista, atemporal y tecnificada del procedimiento a seguir en la sustanciación de las actuaciones arbitrales. De ahí que me pregunte: ¿cómo es que la aplicación de una fórmula relativa a la "sustanciación de las actuaciones arbitrales", operación exquisitamente técnica donde las haya, no pueda ser susceptible de control procesal - y de sus garantías - si previamente se ha convenido que los elementos exclusivamente técnicos de la misma no se sustraen - por su propia naturaleza - al referido control? ¿No estamos ante una aporía?

Estimo que para salir del atolladero nos es urgente revisar la expresión "De la sustanciación de las actuaciones arbitrales" - con la que se rubrica el título V LA y que aparece profusamente en el articulado de la LA - , por cuanto es probable que se corra el peligro de que pueda convertirse en argumento recurrente de los alineados en uno de los bandos que desean extrañar o - mejor aún- preterir al "arbitraje como proceso que es" (Comentarios a la nueva... 2005, p. 239 y ss.).

Tengo para mí, pues, que el óxido del tiempo ha dejado, sin embargo, intacta la carga semántica ( $\mathrm{y}$ beligerante) que transporta la alusión - en el apartado VI de la exposición de motivos de la vigente LA - al "arbitraje como proceso que es" y que, en mi particular y modesta opinión, no deja nada - en absoluto nada - en el limbo de la normatividad.

De ahí que convenga indagar cuál sea la concreta sustancia conceptual que envuelve la locución "De la sustanciación de las actuaciones arbitrales". Y, por fortuna, en el curso de un único trazo jurisprudencial 
se nos brindan - de entrada, y nada menos - una serie de aclaraciones que, aunque solo abocetadas, nos permite hacernos cargo de lo que la tal expresión encierra. Atañe - y lo diré- a las indicaciones del ponente González Olleros, para quien, en la "sustanciación de las actuaciones arbitrales", se siguen "los mismos fundamentos que [se aplican] en los procedimientos comunes de la LEC" -énfasis mío- [J. González Olleros. SAPM de 28 de enero de 2005, en RVDPA, 1, 2006, § 335. Se puede consultar en la web: www.leyprocesal.es, en la sección: Base de datos de jurisprudencia procesal].

Incluso, concedamos que aplicar a la "sustanciación de las actuaciones arbitrales" los mismos fundamentos que operan en la sustanciación de actuaciones encaminadas al ejercicio de la función jurisdiccional mediante el proceso de la misma naturaleza - funcional, se entiende-, consiste en justificar la homogeneidad entre un tipo y otro de sustanciación. O sea, nos encontramos ante el meollo de la finalidad que se acota mediante la "sustanciación de actuaciones arbitrales". Y veamos. La ponente Camazón Linacero lo dice bien claro: "debe tenerse en cuenta que efectivamente rigen en el procedimiento arbitral los mismos fundamentos que en los procedimientos comunes de la Ley de Enjuiciamiento civil en orden a la salvaguarda de los principios de contradicción procesal y defensa" -énfasis mío- [A. Camazón Linacero. SAPM de 30 de mayo de 2006, en RVDPA, 3,2007 , § 376. Se puede consultar en la web: www.leyprocesal.es, en la sección: Base de datos de jurisprudencia procesal].

De ahí se infiere no solo una conclusión a partir de una premisa - como es la relativa a la homogeneidad garantista entre un tipo y otro de sustanciación-, sino fundamentalmente se justifica la corrección de la misma, por la mostrenca razón de que no existen discrepancias que la desvirtúen. No en plan autista, sino dando respuestas con argumentos, como los que utiliza la ponente Camazón Linacero, basados en no "pretender que, por el carácter especial del primero - del procedimiento arbitral, se entiende - y su teórica simplificación de trámites, dejen de observarse tales principios - son los principios de contradicción procesal y defensa - en garantía precisamente de derechos constitucionales" -énfasis mío- [A. Camazón Linacero. SAPM de 30 de mayo de 2006, en RVDPA, 3, 2007, § 376. Se puede consultar en la web: www.leyprocesal.es, en la sección: Base de datos de jurisprudencia procesal].

Y, una vez asumido que en la sustanciación de las actuaciones arbitrales operan las mismas garantías que se aplican a la sustanciación de 
actuaciones encaminadas al ejercicio de la función jurisdiccional, brota la razón que funda, legitima o justifica esa paridad: es la razón garantista. Véase por qué.

Si alguna vez ha sido cierto el dicho de que la "garantía crea la función", al menos ahora nos brinda un precioso auxilio para forjarnos una idea sobre el garantismo en el ámbito de la actuaciones arbitrales. Procede preguntarse, pues, ¿para qué se impone la obligatoriedad legal de la razón garantista?

Pues bien, esa obligatoriedad persigue el mejor funcionamiento del mecanismo procesal del arbitraje. En concreto: con la razón garantista se pretende: a) convencer sobre la justicia del laudo arbitral para mostrar su alcance y facilitar - en su caso - el camino de su anulación; b) y, por extensión, simplificar la resolución de la anulación ante los tribunales, ya que no pocas veces revela los vicios del laudo arbitral que se pronuncie. Todos estos objetivos se congregan dentro de la función endoprocesal del garantismo arbitral.

Pero, además, esta meta garantista apunta también a un principio jurídico-social y que expresa la exigencia de controlabilidad a cargo del pueblo mismo, depositario de la soberanía y en cuyo nombre se ejerce la función jurisdiccional de su control. Henos, pues, en el centro de la función extraprocesal del garantismo arbitral.

Ambas funciones, la técnico-jurídica en orden a favorecer el control jurisdiccional del laudo arbitral, y la social para permitirlo, determinan necesariamente la hechura de la razón garantista en la sustanciación de las actuaciones arbitrales.

Y, al socaire de la taxonomía función endoprocesal-función extraprocesal del garantismo arbitral, resulta que las "formalidades" a seguir en el procedimiento aplicable a las actuaciones arbitrales solo tienen sentido en tanto en cuanto sean respetuosas con las garantías a que se deben - vamos, que le son debidas - y que inspiran la sustantividad del proceso arbitral, como son las de audiencia, contradicción e igualdad entre las partes [el artículo 24 LA tiene la siguiente rúbrica: "principios de igualdad, audiencia y contradicción"]. Y lo diré. Aplicándose la sustantividad procesal de esas garantías, a las que se debe el procedimiento a seguir en las actuaciones arbitrales, las garantías de "aquí y ahora" constitucionales se cumplirían. Y se cumpliría asimismo el deber de tratar a las partes con igualdad y con el también deber de dar a cada una de ellas suficiente oportunidad de hacer valer sus derechos con audiencia y contradicción (artículo 24.1. LA). 
Y una vez trazadas las coordenadas que delimitan la expresión “De la sustanciación de las actuaciones arbitrales" - con la que se rubrica el título V LA-, esas se traducen - de entrada y no tan de pasada - en sendas exigencias garantistas en las que es posible ubicar el carácter debido del proceso arbitral - debido, se entiende, a la existencia de tales garantías - en orden a hacer posible el procedimiento a seguir en la sustanciación de las actuaciones arbitrales.

Pero prosigamos, porque estoy convencido de que voy avanzando. $Y$ ¿por qué? Porque - ya lo hemos visto - la invocación por la vigente LA a la "sustanciación de las actuaciones arbitrales" y no al proceso ni al procedimiento no es determinante, por cuanto la denominada "sustanciación de las actuaciones arbitrales", a que alude la rúbrica del título $\mathrm{V}$ LA, implica la existencia de un procedimiento a seguir en la sustanciación de las actuaciones arbitrales, que se justifica en la sustantividad debida de las garantías que inspiran el proceso de arbitraje en orden a corregir las anomalías aplicativas del procedimiento a seguir -insisto- en la sustanciación de las actuaciones arbitrales. Esa invocación, siendo determinante, se justifica, por lo demás, en la operatividad del principio de autonomía de la voluntad (Comentarios a la nueva... 2005, p. 240 y ss.).

Veamos, y para que se me siga entendiendo. Significa lo anterior que la ordenación del procedimiento [a seguir en las actuaciones arbitrales] queda condicionada al principio de la autonomía de la voluntad de las partes, pero en tanto en cuanto se proceda a la observancia de unos trámites que impliquen el respeto de las garantías procesales a las que se debe el mentado procedimiento arbitral y que son las de audiencia, contradicción e igualdad de las partes, ofreciendo el árbitro a cada una de ellas la suficiente oportunidad de hacer valer sus derechos (artículo 24.1. LA). Y en la anterior afirmación no me quedo solo. En la misma ubicación hermenéutica se sitúa la exposición de motivos de la LA, según la cual "el Título V [de la LA] regula las actuaciones arbitrales". Y vuelvo a incidir en la misma idea expuesta renglones antes:

... la Ley [dice la exposición de motivos de la LA en su apartado VI] vuelve a partir del principio de autonomía de la voluntad y establece como únicos límites al mismo y a la actuación de los árbitros el derecho de defensa de las partes y el principio de igualdad, que se erigen en valores fundamentales del arbitraje como proceso que es. Garantizado el respeto a estas normas básicas, las reglas que sobre el procedimiento arbitral se establecen son 
dispositivas y resultan, por tanto, aplicables sólo si las partes nada han acordado directamente o por su aceptación de un arbitraje institucional o de un reglamento arbitral. De este modo, las opciones de política jurídica que subyacen a estos preceptos quedan subordinadas siempre a la voluntad de las partes [énfasis mío].

Lo cual explica la ineliminable presencia de consideraciones garantistas en la operatividad del mentado principio de autonomía de la voluntad de las partes, lo que, también, confiere legitimidad a su control jurídico. ¡Nada más y nada menos!

\section{Normativa aplicable a la sustanciación garantista de las actua- ciones arbitrales}

A menos que se aliente la bizarrerie de concebir la sustanciación de las actuaciones arbitrales como un mero instrumento procedimental - que no lo es, por lo indicado renglones antes-, habrá que concluir que, según la LA, el tal procedimiento a seguir en la sustanciación de las actuaciones arbitrales ha de ajustarse, en todo caso, al principio de autonomía de la voluntad, que posee, como "únicos límites al mismo", según el apartado VI de la exposición de motivos de la LA,

... el derecho de defensa de las partes y el principio de igualdad, que se erigen en valores fundamentales del arbitraje como proceso que es. Garantizado el respeto a estas normas básicas [sigue indicando la exposición de motivos], las reglas que, sobre el procedimiento arbitral, se establecen son dispositivas y resultan, por tanto, aplicables sólo si las partes nada han acordado directamente o por su aceptación de un arbitraje institucional o de un reglamento arbitral. De este modo, las opciones de política jurídica que subyacen a estos preceptos quedan subordinadas siempre a la voluntad de las partes.

Hay más. Si le diéramos un alcance panorámico al ámbito negocial del arbitraje, que faculta a que la voluntad de las partes presida la ordenación de las actuaciones arbitrales, habría que empezar - de conformidad con el artículo 6 LA - identificando y analizando las pautas de conducta susceptibles de ser regladas por el mentado precepto, habida cuenta de que en él se establece que si una parte, conociendo la infrac- 
ción de alguna norma dispositiva de la LA o de algún requisito del convenio arbitral, no lo denuncia dentro del plazo previsto para ello o, en su defecto, tan pronto como le sea posible, se considerará que renuncia a las facultades de impugnación previstas en la propia LA. Y habría que concluir que la lógica empleada en el mismo, nos empuja a encapsularnos en su microcosmos, donde parece tener acomodo la reflexión de la ponente Fernández Soto al decir que el aludido precepto, en línea con el ámbito negocial del arbitraje que faculta a que la voluntad de las partes presida la ordenación de las actuaciones arbitrales y el arbitraje mismo a través del contenido del convenio arbitral, "no es sino una disposición sobre renuncia tácita a las facultades de impugnación, que obliga a las partes en el arbitraje a la denuncia tempestiva e inmediata de las violaciones de normas dispositivas, esto es, aplicables en defecto de voluntad de las partes" - énfasis mío- [M. Fernández Soto. SAPont de 30 de junio de 2008, en RVDPA, 1, 2009 , § 422. Se puede consultar en la web: www.leyprocesal.es, en la sección: Base de datos de jurisprudencia procesal]. Y ese dato es oro en polvo si hacemos caso a la directiva de si lex non distinguit nec nos debemos distinguere. Entonces, no tendré más cuajo que reconocer que encuentra piso firme en el texto de la LA la pretensión de imponer un criterio interpretativo justificado en el ámbito negocial del arbitraje. A no ser que nos topemos con el carácter "debido" - a la normativa básica ordenadora del arbitraje-, que es garantía del debido proceso arbitral, atinente a los principios esenciales - garantías - de audiencia, contradicción e igualdad entre las partes (artículo 24 LA).

No deseo ser repetitivo. Pero ese sabroso apartado VI de la exposición de motivos de la LA me pone sobre la pista siguiente: que el procedimiento arbitral a seguir en las actuaciones arbitrales se debe - es "debido" - a la normativa básica - que son garantía del debido proceso arbitral - atinente a los principios esenciales de audiencia, contradicción e igualdad entre las partes (artículo 24 LA). Y veamos - ya lo he indicado renglones antes-. Partiendo de esos únicos límites al principio de autonomía de la voluntad, el desarrollo normativo del procedimiento a seguir en la sustanciación de las actuaciones arbitrales se puede regir, o bien por la voluntad de las partes o por las normas establecidas por la institución arbitral a la que se haya encomendado la administración del arbitraje (arbitraje institucional) $o$, en defecto de una y otras, por el acuerdo de los árbitros.

Es cierto. No cabe duda. El artículo 25.1 LA alude a la libertad de las partes en orden a la determinación de las reglas de desarrollo del proce- 
dimiento a seguir en la sustanciación de las actuaciones arbitrales, siempre que se respeten las garantías básicas del debido proceso arbitral. Según el artículo 25.1. LA, las partes pueden convenir libremente el procedimiento al que se hayan de ajustar los árbitros en sus actuaciones. Pero, al propio tiempo, ese precepto no desconoce que las normas sobre desarrollo del procedimiento a seguir en la sustanciación de las actuaciones arbitrales contenidas en los reglamentos de arbitraje de las instituciones arbitrales son, también, determinantes, por lo que las partes dejan de ser los "domini litis" cuando la opción que concurra sea la del arbitraje institucional.

Y, precisamente, para dar curso a lo que pretendo esclarecer (la radical inconcreción de las normas a seguir en la sustanciación de las actuaciones arbitrales y el carácter debido de las mismas a las garantías básicas del debido proceso arbitral), me viene pintiparado indicar cómo las previsiones que se contienen en la vigente LA, en favor del principio de libertad de las partes en orden a establecer las normas de procedimiento a seguir en la sustanciación de las actuaciones arbitrales, son similares a las que, en gran medida, adoptó el modelo de actuaciones arbitrales que seguía la LA de 1988, que, a su vez, era parangonable con el que adoptó, solo en el arbitraje de equidad, la LAP de 1953. No así con el que se estableció para el arbitraje de derecho esa misma LAP de 1953.

Veámoslo. La sustancial identidad entre la LAP y LA de 1988 [y ahora también con la vigente LA], a nivel de modelos procedimentales, fue puesta de relieve jurisprudencialmente a través del ponente Roma Álvarez, con ocasión de la vigencia de la LA de 1988, al decir:

... pese a la inusitada extensión del escrito de impugnación y el de contestación, así como la larga duración de la vista celebrada, puede afirmarse que el problema a resolver no es tan complejo como pudiera parecer a simple vista y en cierto modo todos y cada uno de los problemas planteados han sido ampliamente estudiados por la jurisprudencia recaída a propósito de recursos planteados ante el TS bajo la vigencia de la Ley de 22 de diciembre de 1953, pues como es obvio, tras la promulgación de la Ley 36/1988, de 5 de diciembre, tales cuestiones pasan a ser resueltas en única instancia por las AAPP, aunque los principios que se pudieran calificar de básicos o rectores en una y otra Ley no sufren importantes modificaciones en el sentido de que deba de partirse ex novo. Tal es la opinión a la que se puede llegar examinando lo realizado por los tratadistas que se han ocupado de esta 
materia, pudiendo citarse en este sentido el profesor y Magistrado Javier O'Callagham ("El contrato de compromiso según la Ley de Arbitraje de 5 de diciembre de 1988", Actualidad Civil, enero 1989, epígrafe 1), quien afirma que existen grandes variaciones entre la antigua y la nueva norma, tendente a la simplificación, flexibilización de designación de árbitros y el establecimiento de tres principios esenciales que deben de cumplirse: audiencia, contradicción e igualdad entre las partes, con la determinación de tres fases - alegatoria, probatoria y decisoria - pero lo cierto es que así concebido el arbitraje de equidad en nada varía de lo que establecía el artículo 29 de la derogada Ley (...). Otra opinión autorizada puede ser la de Ortiz Navacerrada ("Ley 36/1988, aspectos procesales", Actualidad Civil, enero 1989, epígrafe 42), quien analiza las novedades que se introducen respecto de la Ley anterior y afirma que se extiende a toda modalidad de arbitraje la libertad procedimental que la anterior sólo atribuía al de equidad, citando diversas sentencias en ese sentido y señalando que se configura un procedimiento muy próximo al que regía para la equidad; finalmente, Serrano Alonso, catedrático y Magistrado (Actualidad Civil, febrero 1989, epígrafe 141), opina sobre la gran relevancia de la voluntad de las partes para fijar el procedimiento arbitral de modo que las normas de la Ley tienen el carácter de exigencias mínimas inderogables, lo cual también es indudable que coincide con los criterios que la constante y reiterada jurisprudencia del TS ha venido manteniendo bajo la vigencia de la Ley de 1953.

Y se añade:

... Ya se ha indicado más arriba, pero conviene puntualizarlo, que el criterio de la Ley nueva en materia de trámites, lo que se podría denominar proceso arbitral, viene a coincidir con lo que la antigua establecía para el arbitraje de equidad, sobre la base de principios de libertad, pero exigiendo el artículo 21 la sujeción a los principios esenciales de audiencia, contradicción e igualdad entre las partes, señalando la voluntad de éstas el desarrollo del procedimiento no existiendo plazos determinados salvo para el laudo, fijando los árbitros plazos preclusivos para formular las alegaciones (art. 25) y siendo los árbitros quienes deciden acerca de la pertinencia de las pruebas (art. 26) [énfasis mío]; con esta base legal se invoca por el impugnante una segunda causa de nulidad, al amparo del artículo 45.2 de la Ley, al no 
haberse observado las formalidades y principios esenciales establecidos por la Ley y que centra en la no fijación de plazos preclusivos para hacer alegaciones, y acordar de oficio una sola prueba, la auditoría a cargo de la firma A.A. en la que se vulneró el principio de igualdad, y practicándose sin citación de los impugnantes... [A. Roma Álvarez. SAPM de 21 de octubre de 1991, en RVDPA, 2, 1993, § 19 (pp. 228 y 229)].

Y lo diré. La airosa salida ofertada por el ponente Roma Álvarez pone de manifiesto que la LA acude a una propuesta procesal - debidaa la esencialidad aplicativa básica y garantista de los principios de audiencia, contradicción e igualdad de las partes (artículo 24 LA). A través de ellos y con ellos se hace el procedimiento a seguir en la sustanciación de las actuaciones arbitrales, en modo tal que, a falta de acuerdo de las partes, que siempre ha de respetar la esencialidad aplicativa básica y garantista de esos principios, los árbitros pueden - con sujeción a esa esencialidad aplicativa básica y garantista - dirigir el arbitraje del modo que consideren apropiado (artículo 25.2. LA).

Si se fija bien el paciente lector, la propuesta de la LA acerca del desarrollo normativo del procedimiento arbitral a seguir en la sustanciación de las actuaciones arbitrales se justifica en el respeto del principio de autonomía de la voluntad de las partes [el artículo 25.2. LA dice que "a falta de acuerdo, los árbitros podrán, con sujeción a lo dispuesto en la presente Ley - es la esencialidad aplicativa básica y garantista de los principios de igualdad, audiencia y contradicción a que alude el artículo 24 LA - , dirigir el arbitraje del modo que consideren apropiado"]. La LA reconoce la autonomía de la voluntad de las partes en el arbitraje ad hoc o libre, y en las instituciones arbitrales en orden a normar la administración del arbitraje (arbitraje institucional). Solo en defecto de ambos planos de desarrollo normativo autónomo del procedimiento a seguir en la sustanciación de las actuaciones arbitrales, se reconoce expresamente a los árbitros la capacidad de normar en materia de sustanciación de actuaciones arbitrales, siendo esta última opción la prevalente en el derecho comparado. En efecto, en la mayor parte de las legislaciones sobre arbitraje se reconoce al árbitro o árbitros la facultad de establecer las reglas por las que han de tramitarse las actuaciones arbitrales.

Admitámoslo. La razón del reconocimiento legislativo a favor de la capacidad normativa del árbitro para desarrollar el procedimiento a seguir en la sustanciación de las actuaciones arbitrales, en la línea de la aplica- 
ción de garantías procesales consideradas de consuno indisponibles, se justifica en la superación del arbitraje como una "jurisdicción especial" y, por tanto, de las denominadas teorías jurisdiccionalistas que le asimilaban a una modalidad jurisdiccional más de administrar justicia que, por tal razón, se hallaba vinculada por principios y trámites de procedimiento que serían indisponibles para los árbitros como si se tratara de un orden jurisdiccional más, tal y como sucedía con el arbitraje derecho en la LAP de 1953 para esa misma modalidad de arbitraje. El abandono de la explicación jurisdiccionalista del arbitraje y el acogimiento de la tesis negocial por mí postulada justifica, en nuestro derecho de arbitraje, el desarrollo normativo de unas actuaciones arbitrales disponible para las partes y también para los propios árbitros (artículo 25.2. LA), aunque las facultades de los árbitros no van a ser absolutas. Van a tener el contrapunto de la actividad de las partes o de las propias instituciones arbitrales que pueden imponer a los árbitros las reglas de procedimiento a seguir en la sustanciación de las actuaciones arbitrales. Pero, si se observa bien, técnicamente no se trata de un obstáculo, sino justamente de una consecuencia natural de la autonomía de la voluntad que justifica el arbitraje mismo y, como tal, unánimemente admitida también en la LA, que, al autorizar a las partes y a las instituciones arbitrales a desarrollar normativamente la sustanciación de las actuaciones arbitrales, limita - hay que decirlo - indirectamente la libertad de los árbitros.

Pero no deseo desviar la atención del lector, ya que si bien es posible convenir libremente el procedimiento a seguir en las actuaciones arbitrales, la esencialidad aplicativa básica y garantista de los principios de audiencia, contradicción e igualdad de las partes al que han de ajustarse - es preceptivo - la sustanciación de las actuaciones arbitrales (artículo 24.1. LA), surge en la LA con una originalidad de tal índole que, sin duda, no es posible hallarla en el resto de nuestro ordenamiento jurídico procesal.

Si se acoge esta impostación, no tendré más cuajo que reconocer que la opción no es procedimental o la propia de un principio de legalidad procedimental de inexcusable aplicación en la sustanciación de las actuaciones arbitrales. Es, en cambio, procesal y debida a las garantías que lo hacen posible - el debido proceso arbitral, se entiende-. Pero la opción, si bien es original, cuenta con antecedentes. No es posible olvidar que la LAP de 1953 no sometía el procedimiento de equidad a forma legal alguna (artículo 29 LAP) y que la LA de 1988 adoptó una opción muy similar a la actual, sin olvidar que la eliminación del principio de legalidad procedimental res- 
ponde en el arbitraje comercial internacional a una práctica ampliamente extendida.

Y eso es lo que justamente sucede en la práctica arbitral. Por ello, no sigue siendo ocioso indicar que la esencialidad sustantiva de los principios procesales del debido proceso arbitral supone la convergencia, en la sustanciación de las actuaciones arbitrales - una vez respetada la esencialidad sustantiva y de garantía -, con un ámbito de derecho imperativo (ius cogens). Su inobservancia provoca la anulación del laudo arbitral.

Y si ha imperado el consenso sobre este particular, entonces me siento singularmente impelido para afirmar que en LA se establecen pautas sustantivas y garantistas de procedibilidad de las actuaciones arbitrales que tanto las partes y las instituciones arbitrales, por un lado, como los árbitros, por otro, han de aplicar. Son - nuevamente he de decirlo- las de los artículos 24.1. LA. En la LA esas pautas sustantivas y garantistas de procedibilidad de las actuaciones arbitrales presentan una indudable proyección de orden público. Significa que existe un núcleo procesal irreductible en la LA, cuyo incumplimiento supone vulnerarla, justo porque son normas procesales de garantía. En consecuencia, también en la LA existe orden público procesal susceptible de ser vulnerado.

Y hay que decirlo claro. La orientación de la LA, a diferencia de la que asumió en su día la LAP de 1953, es de orden público procesal esencial y garantista, ya que, en caso contrario, no podría ser garantía (garantismo) para un correcta sustanciación de las actuaciones arbitrales. El irreductible núcleo procesal de garantía con el que opera la LA es absolutamente esencial e imperativo, por lo que no es posible derogarlo. En la LA poseen ese carácter los principios esenciales de audiencia, contradicción e igualdad entre las partes, a los que, en todo caso, ha de ajustarse el procedimiento arbitral (artículo 24 LA), ya que, según el artículo 24.1. LA, “deberá tratarse a las partes con igualdad y darse a cada una de ellas suficiente oportunidad de hacer valer sus derechos". El carácter esencial y garantista de tales principios justifica la posibilidad de pedir la anulación del laudo arbitral pronunciado infringiéndolos.

De ahí que la LA no vincula la anulación del laudo arbitral a cualquier infracción garantista, sino a las esenciales, postuladoras de la existencia de un garantismo procesal en el arbitraje.

Basta con que una parte reclame la esencialidad de ese núcleo procesal garantista irreductible, para que el árbitro se halle obligado a aplicarlo. La esencialidad garantista del núcleo procesal irreductible, que sanciona la LA, 
permite la sustanciación de las actuaciones arbitrales conforme a lo indicado en el artículo 24.1. LA, que alude a las normas y principios de obligado cumplimiento de aplicación a esa sustanciación. Con arreglo a esas normas y garantías de obligado cumplimiento, el arbitraje será eficaz.

Pero hay más. La esencialidad eficaz de la sustanciación de las actuaciones arbitrales no es jurisdiccional. El arbitraje se caracteriza por plantear una vertiente no jurisdiccionalizada del garantismo. Pero tan constitucional es la tutela judicial efectiva que prestan juzgados y tribunales, como la tutela procesal efectiva que prestan el árbitro o árbitros mediante la sustanciación de actuaciones arbitrales, lo que indudablemente implica una irreductible esencialidad procesal garantista para hacerla posible, pero, obviamente, no jurisdiccionalizada, que permite conceptuarlo [al procedimiento a seguir en la sustanciación de las actuaciones arbitrales] a través de un referente esencialmente procesal que se proyecta básicamente hacia la verificación de su sustantividad material "de aquí y ahora" a través de la actividad que el árbitro o árbitros llevan a cabo mediante el trámite técnico, acrítico, mecanicista y atemporal del procedimiento a seguir en la sustanciación de las actuaciones arbitrales.

La conclusión no se hace esperar. El proceso arbitral es sustantividad - garantista - que neutraliza la atemporalidad mecanicista del procedimiento a seguir en la sustanciación de las actuaciones arbitrales. Por ello, al final se halla el proceso y su sistema de garantías que, según la LA, son esencialmente tres: audiencia, contradicción e igualdad entre las partes (artículo 24 LA).

Partiendo de un referente funcional troncalmente procesal y garantista, pero, al propio tiempo, no jurisdiccionalizado, se construye la normativa aplicable a las actuaciones arbitrales, sobre la base de la existencia de un proceso arbitral debido a las garantías de "aquí y ahora" [constitucionales] y sustantivo por su carácter debido, al que ha de acomodarse la tramitación procedimental de las actuaciones arbitrales.

Nos hallamos, pues, en un entorno temático en el que bulle aquel mentado carácter convergente al que aludí renglones antes, y que significa que en la sustanciación de las actuaciones arbitrales ha de confluir la esencialidad garantista de sus principios normadores, lo que supone, a la postre, la entrada en conclusiones de muy diversa índole. Veamos algunas de ellas.

Por lo pronto, hay que excluir el cómputo diverso de plazos. Esto es, que a una parte se le conceda para alegación veinte días y a la otra ocho, 
por poner un ejemplo. O bien, que quede preterida la audiencia y contradicción, impidiéndose a una parte tener conocimiento de lo alegado y probado por la contraparte al no dársele traslado para obtener ese conocimiento. Esa es la tesis que planteó el ponente Belo González con ocasión de la vigencia de la LA de 1988, al indicar:

... en el procedimiento arbitral se han observado los principios de contradicción (es la garantía o la cautela encaminada a que las partes puedan efectuar un auténtico debate, con la debida posibilidad de formular sus contestaciones o réplicas ante las posiciones del contrario) y de igualdad (en base al principio de igualdad el procedimiento arbitral debe brindar a las partes "igualdad de armas" en el arbitraje, sin ningún tipo de desequilibrio a favor de una de ellas) [R. Belo González. SAPM de 11 de noviembre de 1997, en RVDPA, 2, 1999, § 175 (p. 382)].

Pero no nos engañemos. El antiformalismo y flexibilidad en la sustanciación de las actuaciones arbitrales que, en la esencialidad garantista de los principios procesales del arbitraje, introduce el pacto de las partes o la reglamentación institucional, implica preterir la antiesencialidad de la normativa arbitral. En la determinación de las reglas a las que los árbitros deben de atender para la sustanciación de las actuaciones arbitrales no se puede, convencionalmente, imponer la observancia de disposiciones procedimentales inaplicables, o que no se acomoden a las garantías del arbitraje, en cuanto que puedan ser incompatibles con esas mismas garantías esenciales del arbitraje. Las partes tampoco pueden alterar convencionalmente los límites fijados como inderogables y garantistas por ser propios de la esencialidad del debido proceso arbitral, y que no son otros que los que se contienen en el artículo 24.1. LA.

Y vuelvo a la carga y - espero- a no ser cargante: el cumplimiento de los límites en la sustanciación de las actuaciones arbitrales establecidos en el artículo 24.1. LA es inderogable y, por tanto, el antiformalismo no puede sustentar el antiprocedimentalismo que no es debido con las garantías del proceso arbitral. Es la tesis que también adoptó con la vigencia de la LA de 1988 el ponente Piñol Rodríguez, al decir:

El convenio arbitral supone una voluntad por parte de los que lo formalizan, de dirimir sus discordias, a través de un árbitro, sin acudir a 
la vía judicial y sin que de ello pueda deducirse o presuponer una dejación porque esa decisión se adopte sin formalismos, el procedimiento es obligado por la Ley de Arbitraje y debe ser escrupulosamente cumplido, por cuanto que no hay razones, ni de indole práctico, ni derivadas de la voluntad de los sujetos que se someten, para considerarlo secundario, antes bien, y dada la gran capacidad decisiva que se concede al árbitro, es obligado por seguridad de todos, que el procedimiento sea con rigor cumplido, en lo que es exigible, pues esa decisión lo debe ser en base a que las partes hayan podido alegar y probar, y con ello evitar una decisión arbitraria injustificada [énfasis mío] [C.M ${ }^{a}$ Piñol Rodríguez. SAPSe de 18 de enero de 1993, en RVDPA, 2, 1996, § 70, p. 284].

Del anterior irreprochable comentario desearía destacar que la inobservancia, por el árbitro, de la esencialidad garantista del debido proceso arbitral, supone cuestionar la eficacia del laudo arbitral que se pronuncie. Esa inobservancia puede justificar la anulación del laudo arbitral, siempre que esa consecuencia no sea contraria a la necesaria proporción entre la infracción y la sanción, a la luz de las exigencias de utilidad y economía - mesura iuris est utilitas - o de las exigencias de la buena fe, en su manifestación objetiva o ética, en tanto en cuanto pueda evitarse mediante la doctrina de la conservación del acto -actus intelligendi sunt potius ut valeat quam ut pereat - (Cfr. SAPB de 2 de diciembre de 1994, en RVDPA, 2, $1996, \S 86$, p. 317 y ss.).

Voy ahora a por la segunda conclusión. Es esta. En el desarrollo de esa esencialidad garantista del debido proceso arbitral, si bien los árbitros pueden "dirigir el arbitraje del modo que consideren apropiado" (artículo 25.2. LA), no es menos cierto que, al ser básica y garantista, han de actuar con sujeción a ella. Desde esa vertiente, el principio de audiencia supone oír a las partes. La esencialidad del principio de audiencia comprende tanto el derecho de alegar como de probar. Y la provocada falta de audiencia origina indefensión. Pero, para que esa indefensión posea relevancia, ha de ser real y efectiva $y$, además, tiene que probarse que efectivamente se produjo. La misma tesis planteó el ponente Ferrer González con ocasión de la vigencia de la LA de 1988, al decir:

... en segundo lugar se alega la infracción de los principios de audiencia, contradicción e igualdad entre las partes por: $1^{\underline{0}}$ No haber dado traslado al hoy recurrente de las alegaciones de la contraria. $2^{\underline{o}}$ No 
“habérsele dado la oportunidad de proponer algún medio probatorio que resultase de su interés pese haber solicitado en su escrito de demanda o alegaciones previas que se recibiera a prueba el arbitraje instado con lo cual se le causó una grave indefensión". 3ํ№ haberse practicado prueba alguna a su instancia o con su intervención. El principio de audiencia es un principio general del derecho que garantiza que nadie pueda ser condenado sin ser oído y vencido en un juicio; en un sentido amplio abarcaría tanto el derecho a alegar o exponer los argumentos (fácticos, jurídicos) que apoyan la pretensión como el derecho a proponer, y practicar, la prueba necesaria de lo que se alega. En la Ley de Arbitraje el principio aparece recogido con tal extensión en sus artículos 21 y 26. Entrando ya a conocer de la primera de las quejas del recurrente en relación con el procedimiento arbitral objeto de impugnación ha de señalarse que aquel fue la única parte que formuló pretensiones de condena (al pago de parte del precio de un contrato de obra) y que en apoyo de las mismas tuvo la oportunidad de presentar escrito que se hizo llegar al árbitro en fecha 31 de mayo de 1999 limitándose la parte contraria a oponerse en su escrito de alegaciones a la petición de condena, por lo que el derecho de audiencia de aquel no se habría visto desconocido por la simple falta de traslado del escrito de la contraria pues el derecho no extiende a poder alegar y rebatir a su vez los concretos motivos de oposición de aquel cuya condena se pide. Nada impedía a la parte hoy recurrente haber propuesto, en el escrito de alegaciones iniciales, las pruebas que estimase oportunas para acreditar los hechos en que fundamentaba sus pretensiones, de hecho basta leer tal escrito para apreciar que con el mismo acompañó una abundante prueba documental (hasta 26 documentos distintos). Cierto es que, una vez que en el escrito de alegaciones iniciales se pidió expresamente el recibimiento a prueba del procedimiento el árbitro debió acordar el mismo o, en caso contrario, comunicar a las partes porque consideraba innecesario la práctica de pruebas distintas a la documental ya aportada para así dar oportunidad a las partes de hacer alegaciones frente a su decisión. Ahora bien para que tal vicio procedimental pueda tener entidad suficiente para entender que ha supuesto una vulneración del derecho de defensa es necesario que haya causado una real y efectiva indefensión material del recurrente por lo que a este correspondía la carga de acreditar la misma no solo señalando en el escrito de recurso qué pruebas pretendía practicar y su relación con los hechos alegados sino también demostrando la relevancia de las mismas para la resolución de la controversia [énfasis mío] (en este sentido, 
ss. TC 149/1987, 167/1988, 141/1992, 35/1993 y 170/1998, entre otras). Al no haber siquiera el recurrente alegado qué pruebas le impidió proponer la falta de recibimiento a prueba del procedimiento no puede estimarse que tal falta le haya causado indefensión [J. Ferrer González. SAPont de 25 de septiembre de 2000, en RVDPA, 3, 2002, § 290. Se puede consultar en la web: www.leyprocesal.es, en la sección: Base de datos de jurisprudencia procesal].

Obsérvese que la esencialidad garantista de la audiencia de las partes es la que responde tanto a una propuesta básicamente oral como escrita y, por lo tanto, ya sea con las palabras o con la escritura, es una esencial garantía oír a las partes.

Voy ahora a por la tercera conclusión. Y paso a referirme a la garantía de la contradicción como la consecuencia inequívoca de prestar audiencia a las partes. Técnicamente no es posible que se pueda contradecir si antes no existen argumentos que justifiquen la contradicción. La esencialidad garantista de la contradicción de las partes es la que, justificada en la audiencia, ya sea oral o escrita, evita la indefensión de la partes.

Por último, aludir a la esencialidad garantista del principio de igualdad como la que permite que las partes dispongan de unos mismos medios para defender sus posiciones parciales. Es la tesis que también postuló el ponente García García con ocasión de la vigencia de la LA de 1988, al decir:

... el principio de igualdad, en la vertiente que ahora nos interesa, exige, simplemente, que las partes del proceso especial de arbitraje dispongan de los mismos medios para defender sus posiciones, esto es, de iguales derechos, de parejas posibilidades para sostener o fundamentar lo que cada una estime conveniente, debiendo gozar las partes de una posición equivalente en el plano procesal, en definitiva, de unas mismas oportunidades o de un mismo trato a la hora de alegar y poder acreditar lo que sostienen [A. García García. SAPVizc de 19 de febrero de 1999, en RVDPA, 1, 2000, § 218, p. 115. Se puede consultar en la web: www.leyprocesal.es, en la sección: Base de datos de jurisprudencia procesal].

Y todo lo indicado renglones antes es lo que resplandece en lo tocante a la esencialidad garantista del arbitraje, y lo que hace que este tenga una hechura especifica sin que nos salga ningún tiro por la culata. 


\section{Forma de las actuaciones arbitrales}

La exigencia de formas en el arbitraje, con apoyo en la esencialidad básica y garantista - no jurisdiccionalizada - de las garantías de audiencia bilateral, contradicción e igualdad (artículo 24 LA), asume, en la LA, plena libertad en orden a la sustanciación de las actuaciones arbitrales sobre la base de lo que las propias partes o el árbitro o los árbitros (art. 25.1. y 2. LA) o, en fin, la institución arbitral establezcan, sin que exista en la LA un sistema normativo - formalmente delimitado, se entiende- de sustanciación de las actuaciones arbitrales de referencia, lo que a su vez no implica en modo alguno arbitrariedad en la adopción del mismo (Comentarios a la nueva... 2005, p. 249 y ss.).

En evitación de malentendidos, el ponente Salcedo Gener adjunta un par de precisiones más. La primera, que "los procesos - arbitrales, se entiende- están basados en los principios de libertad y flexibilidad para las partes y para los árbitros y no en los principios de preclusión y dispositivo más propio de los procesos judiciales" - énfasis mío- [J.M. Salcedo Gener, SAPM de 13 de junio de 2007, en RVDPA, 3, 2008, § 403. Se puede consultar en la web: www.leyprocesal.es, en la sección: Base de datos de jurisprudencia procesal]. Y la segunda, que "los arbitrajes se rigen por las disposiciones de la Ley de Arbitraje y no por los de la Ley de Enjuiciamiento Civil" -énfasis mío- [J.M. Salcedo Gener, SAPM de 13 de junio de 2007, en RVDPA, 3, 2008, § 403. Se puede consultar en la web: www.leyprocesal.es, en la sección: Base de datos de jurisprudencia procesal].

No debió estar muy bullente la deliberación del ponente Salcedo Gener en la que se coció su ponencia, a juzgar por el tenor de sus indicaciones, que intentan reducir a papilla el presumible carácter heterorreferente de las actuaciones arbitrales. De entrada, llama poderosa y positivamente la atención el común denominador de las mismas. Es, simplemente, apabullante. No existe tendencia al raquitismo y a la bajura de datos normativos, confirmando, así, la pervivencia de una cultura arbitral que pone al arbitraje al servicio de paradigmas garantistas y silencia la dimensión transformadora que supondría la irrupción y consolidación de un régimen legal incondicionalmente fiel a la LEC.

Veamos. No ha de perseguirse sin más, por supuesto, agobiar a tal o cual ámbito normativo de la LA, enredándolo en la jungla de preceptos legales de la LEC.

Y, en evitación de malentendidos, no está de más partir de la siguiente afirmación: el modelo procesal autorreferente que adopta la LA en 
cuanto a las formas de las actuaciones arbitrales se sustenta sobre la base de la obtención de la tutela procesal efectiva en orden a que en ningún caso se produzca indefensión (artículo 24.1. LA), consistiendo la indefensión en una impuesta falta de oportunidad para comparecer, alegar y probar en el arbitraje.

Pero, jojo!, la tutela procesal efectiva que debe ofertar el árbitro puede, en cambio, ser diversa en cuanto al procedimiento a seguir en la sustanciación de las actuaciones arbitrales, en la medida en que es posible optar por la oralidad o por la escritura siempre que se respeten los principios esenciales $-y$ debidos del proceso arbitral garantista - que sustentan el sistema de garantías debidas para configurar el proceso arbitral que se ha pergeñado en el artículo $24 \mathrm{LA}$.

En efecto, una vez desgajado el recortable (los antedichos principios esenciales $-y$ debidos del proceso arbitral garantista - que sustentan el sistema de garantías debidas para el proceso arbitral que se ha pergeñado en el artículo 24 LA), y convertidos en referencia absoluta y cerrada, deviene un universo de formas no tan intangible.

Y, ya descendiendo al detalle, la cuestión formal del carácter oral o escrito en la forma de las actuaciones arbitrales, no deja de plantear problemas. En principio, se puede partir de una u otra conceptuación, ya sea oral o escrita, pero la cuestión que ahora se plantea es otra diferente: si se está por un modelo oral de sustanciación de las actuaciones arbitrales, el árbitro en una o varias comparecencias principales podría dar por terminado el arbitraje y su resolución mediante laudo, por lo que, en tales casos, no tendría que resolver sobre la continuación del arbitraje mediante una obligada actividad resolutoria que hiciera posible su desarrollo y, en consecuencia, no tendría que actuar interlocutoriamente, de modo similar a como lo hace el juez estático. Por contra, si se está por un modelo básicamente escrito en el desarrollo del arbitraje, el árbitro se hallaría obligado, sin duda, a pronunciar resoluciones interlocutorias que posibilitarían el desarrollo de las actuaciones arbitrales, a lo que se une que la LA ni indica cómo han de llamarse tales resoluciones interlocutorias del árbitro, ni la forma que han de adoptar, ni tampoco si han de ser motivadas.

Pues bien, no voy a dejarme prender por tales cuestiones de índole eminentemente práctica. Pero diré que la solución de la oralidad ofrece indudables ventajas por su inmediación y por la posibilidad de que el árbitro pueda resolver, incluso los posibles incidentes, sin necesidad de dejar constancia exclusivamente interlocutoria. Pero, advierto. Tanto si 
se sigue un modelo oral como escrito de sustanciación de las actuaciones arbitrales, y siempre que se respeten los principios esenciales del debido proceso sustantivo arbitral, la LA deja bien claro que el criterio formal a seguir en su configuración básica va a ser el que la propia voluntad de las partes establezca o el que se determine en los reglamentos de arbitraje de cada institución arbitral o, en defecto de ambos, el que se establezca mediante acuerdo de los propios árbitros (artículo $25 \mathrm{LA}$ ).

Cae de su peso, pues, que me permita el paciente lector, en estas últimas palabras a modo de epílogo, decir que el ánimo que me ha reconfortado a lo largo del presente trabajo ha sido extraer algo más que un cierto rendimiento exprimiendo preceptos y jurisprudencia. Sinceramente, ¡no lo dude en ningún momento! 


\section{Bibliografía}

M. ${ }^{a}$ Lorca Navarrete. Comentarios a la nueva Ley de Arbitraje 60/2003 de 23 de diciembre. 9. ${ }^{a}$ reimpresión. San Sebastián: Ediciones Instituto Vasco de Derecho Procesal/ Corte Vasca de Arbitraje, 2005. 